\title{
Dilatation And Curettage (D\&C) In A Patient With Spontaneous Pneumothorax
}

\author{
Renju Ninan ${ }^{1}$, NithinSathyan ${ }^{2}$, Ayaskanth.Sahoo ${ }^{3}$, Abraham A.A \\ ${ }^{4,}$ O.T.Vasantha ${ }^{5,}$ Habib.Rahaman.A.A ${ }^{6,}$ \\ Suranjith.Sorake ${ }^{7}$ Ferhan.Ahmed.Khan ${ }^{8}$ S.Padmanabha ${ }^{9}$ \\ 1,2,3,4,5,6,7,8,9 Yenepoya Medical College, Yenepoya University Deralakatte Mangalore-575018 India
}

\begin{abstract}
A 19year old primigravida with 12 weeks gestation was admitted in our hospital with bleeding per vagina $(P V)$. She also complained of dyspnea, fatigue, chest pain. Her $x$-ray chest PA view showed evidence of pneumothorax. Emergency Inter costal drainage (ICD) was placed. . After 24 hours she was posted for dilatation and curettage. General Anaesthesia was administered using injection $1 \mathrm{mg}$ butorphanol, $100 \mathrm{mg}$ propofol and $20 \mathrm{mg}$ atracurium. Airway was secured with size 3 laryngeal mask airway (LMA). At the end of the procedure patient was reversed with neostigmine and glycopyrolate and shifted to MICU without any complication
\end{abstract}

Key words: Dilatation and Curettage, General Anaesthesia,Pneumothorax.Inter costal drainage, Thoracotomy

\section{Introduction}

Spontaneous pneumothorax during pregnancy is a rare condition. Few cases has been reported previously in the literature. There is no universal guideline for management of this condition. Treatment option include conservative management with inter costal drain (ICD) and surgical management in the form of thoracotomy or Video assisted thoracoscopy (VATS)

\section{Case history}

A 19 year old primigravida with 12 weeks gestation was admitted in our hospital with bleeding per vagina (PV). She also complained of dyspnea, fatigue, chest pain. After investigations (fig:1) she was diagnosed to have spontaneous pneumothorax. Emergency Inter costal drainage (ICD) (fig:2) was placed under local anaesthesia. Her symptoms were improved and after 24 hours she was posted for dilatation and curettage.

\section{Anaesthetic management}

Patient was reassesed in the morning after obtaining written inform consent and kept nil per orally for liquids 3 hours before induction of anaesthesia .IntravenousRanitidine $50 \mathrm{mg}$, Intramuscular Glycopyrolate 0.2 $\mathrm{mg}$ were given as pre medication. General Anaesthesia was administered with $1 \mathrm{mg}$ butorphanol , $100 \mathrm{mg}$ propofol and $20 \mathrm{mg}$ atracurium. Airway was secured with size 3 laryngeal mask airway (LMA) (fig:3). Anaesthesia was maintained with $30: 70 \mathrm{O}_{2}: \mathrm{N}_{2} \mathrm{O}$ and $1 \%$ sevoflurane. At the end of the procedure patient was reversed with neostigmine and glycopyrolate and shifted to intensive care area for observation. 3 days later ICD was removed and patient was discharged home without any complication

\section{Discussion}

Primary spontaneous pneumothorax is defined as air in the pleural space that is between lung and chest wall. Spontaneous pneumothorax in pregnancy is extremely rare,with only 55 cases reported till now $[1][2][5][6][7][8][9][10]$. Review of cases showed that the patients are young between age group 20-30 years [11]. Pneumothorax occurred during first and second trimester in 51\%and during perinatal period in $49 \%$ of patients [4]. In $29.6 \%$ patients initial treatment was observation, intercostal drainage in $66.6 \%$ and thoracotomy in $3.8 \%$ of patients. The aeitiology of most pneumothorax occurring in pregnancy is rupture of apical blebs or bullae [11]. Signs and symptoms of pneumothorax include chest pain,progressivehypoxemia,tachycardia and respiratory distress [10]. Diagnosis of pneumothorax can be confirmed by chest radiograph and it is safe to proceed with standard chest radiography with abdominal shield without placing the fetus at substantial risk from ionizing radiation [2]. Treatment of acute pneumothorax in pregnancy or labour is identical to that of nonobstetric patients. Large pneumothorax (more than 20\%) should be treated with tube thoracostomy[13]. Other treatment options are needle aspiration, needle decompression, pleurodesis,thoracotomy and thoracoscopyforrecurrent,persistent or bilateral pneumothorax [7] 


\section{Conclusion}

Recurrent or persistent pneumothorax during pregnancy can be successfully managed by either thoracotomy or thoracoscopy. Safety of the procedure will be enhanced by appropriate anesthetic management, perioperative monitoring of the patient, therapy to inhibit preterm labor (when needed), and careful surgical technique.

\section{Journal Papers}

\section{References}

[1] Wong MK, Leung WC, Wang JK, Lao TT, Ip MS, Lam WK, et al. Recurrent pneumothorax in pregnancy: What should we do after placing an intercostals drain. Hong Kong Med J. 2006;12:375-80.

[2] Gorospe L., Puente S., Madrid C., Novo S., Gil-Alonso J. L., Guntinas A. 2002.Spontaneous pneumothorax during pregnancy. South Med J.95: 555-558.

[3] A. Menon, V. Anikin: Spontaneous Pneumothorax DuringLabour. The Internet Journal of Gynecology and Obstetrics.2007 Volume 7 Number 2. DOI: $10.5580 / 434$

[4] Harton JM, Brown AG, Davidson IT. Post partum pneumothorax: two case reports and discussion. International Journal of Obstetric Anesthesia. 2000 Oct;9(4):286-9.

\section{Books}

[5] Reid CJ, Burgin GA. Video-assisted thoracoscopic surgical pleurodesis for persistent spontaneous pneumothorax in late pregnancy. Anaesth Intensive Care.( 2000;28:208-10)

[6] Wright JD, Powell MA, Horowitz NS, Huettner PC, White F, Herzog TJ. Placental site trophoblastic tumor presenting with a pneumothorax during pregnancy.Obstet Gynecol. (2002;100:1141-4)

[7] Yoshioka H, Fukui T, Mori S, Usami N, Nagasaka T, Yokoi K. Catamenial pneumothorax in a pregnant patient. Jpn J ThoracCardiovasc Surg. (2005;53:280-2)

\section{Report and review of the literature}

[8] Van Winter JT, Nichols FC, 3rd, Pairolero PC, Ney JA, Ogburn PL., Jr Management of spontaneous pneumothorax during pregnancy: Report and review of the literature. Mayo Clin Proc. (1996;71:249-52)

[9] Toyoda K, Matsumoto K, Inoue H, Komori M, Fujita M, Hashimoto S, A pregnant woman with complications of lymphangioleiomyomatosis and idiopathic thrombocytopenic purpura. Intern Med. (2006;45:1097-100)

[10] Sills ES, Meinecke HM, Dixson GR, Johnson AM. Management approach for recurrent spontaneous pneumothorax in consecutive pregnancies based on clinical and radiographic findings. J Cardiothorac Surg. 2006;1:35

[11] Lal A, Anderson G, Cowen M, Lindow S, Arnold AG. Pneumothorax and pregnancy.Chest. 2007;132:1044-8.

[12] Nakamura H, Konishiike J, Sugamura A, Takeno Y. Epidemiology of spontaneous pneumothorax in women. Chest.1986;89:378-82

[13] Gueirn JM, Barbotin-Larrieu F, Meyer P, Habib Y. Pneumothorax in pregnancy: Apropos of 3 cases. Rev PneumolClin. 1988;44:297-9.

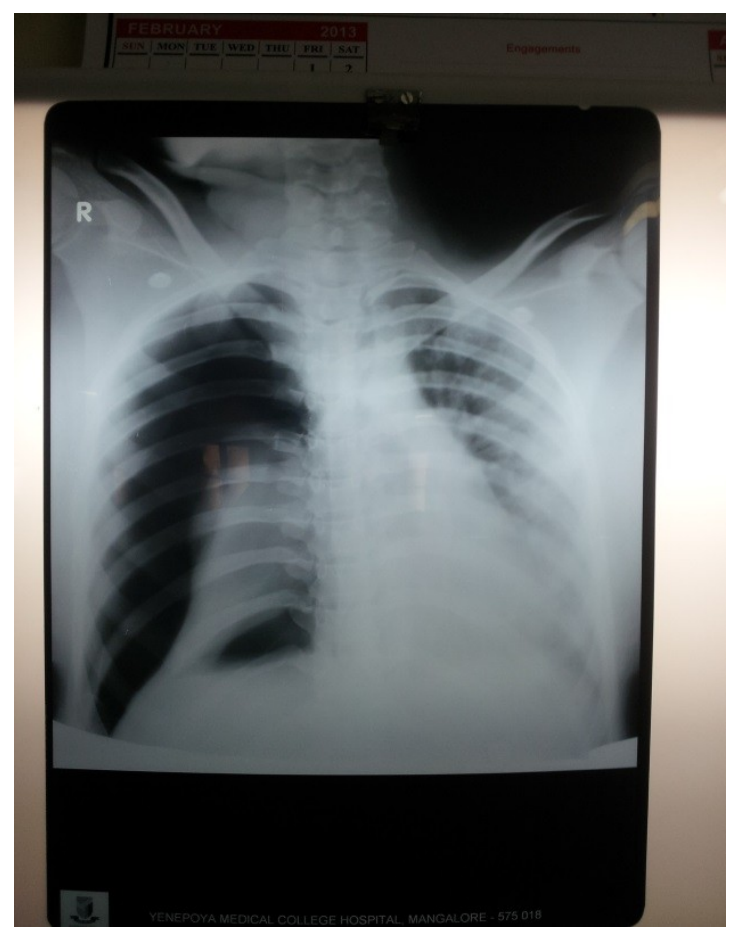

Fig:1 Pneumothorax on chest $\mathbf{x}$-ray (investigation) 


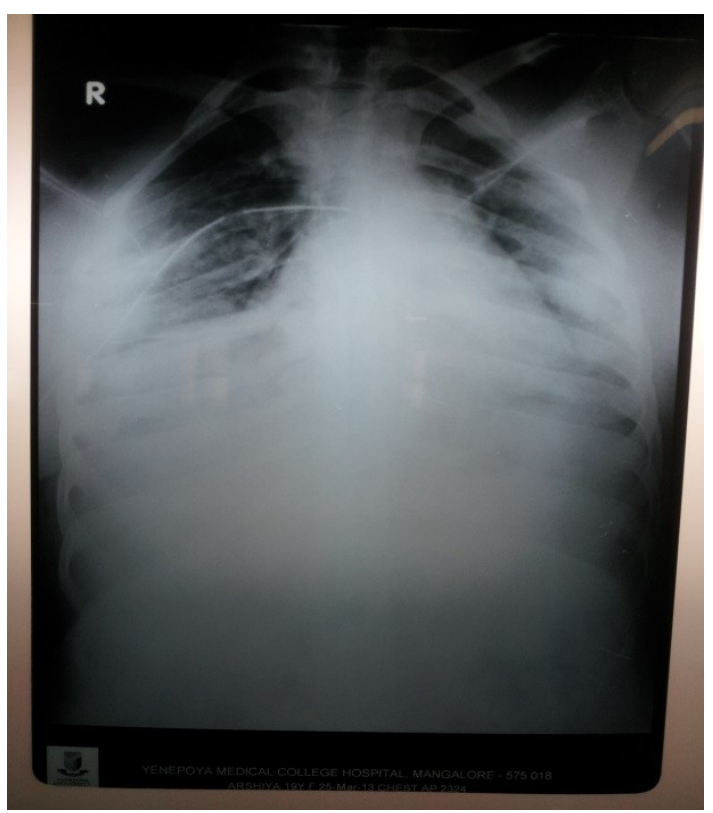

Fig:2 Chest $\mathbf{x}$-ray after placing intercostal drainage

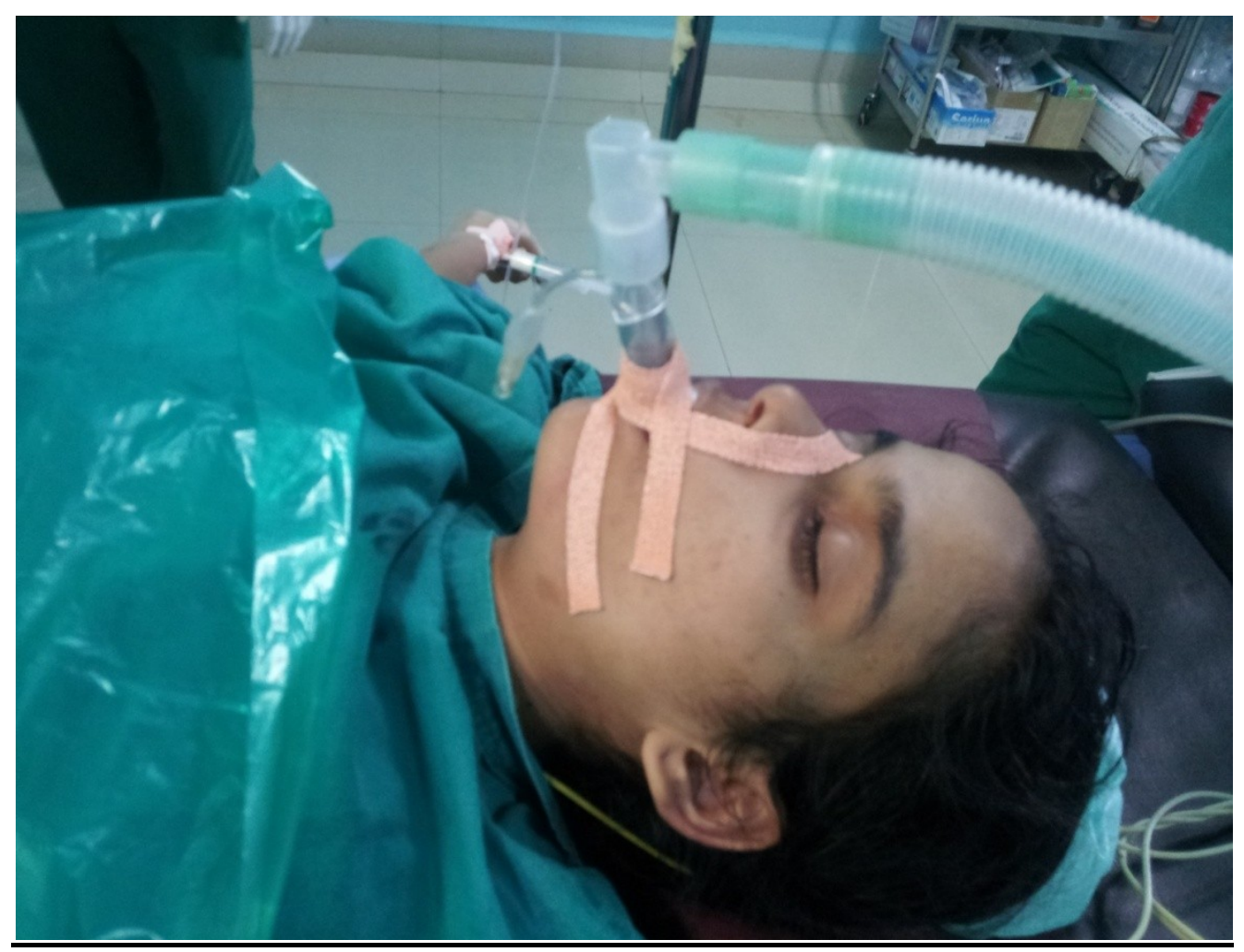

Fig: $3_{\text {After induction and intubation with LMA (Laryngeal Mask Airway) }}$ 